\title{
The presence of methanol in alcoholic beverages analyzed using qualitative method
}

\author{
Diah Navianti ${ }^{1 a^{*}}$, Muhammad Ihsan Tarmizi $^{1}$, Sinta Nur Holifah ${ }^{2}$ \\ ${ }^{1}$ Medical Laboratory Technology, Poltekkes Kemenkes Palembang, Indonesia \\ ${ }^{2}$ The Indonesian Red cross Society Palembang - South sumatera, Indonesia \\ a Email address: dnaviantidiah9@gmail.com
}

\section{HIGHLIGHTS \\ Methanol was still present in alcoholic drinks sold in markets}

\section{ARTICLE INFO}

\section{Article history}

Received date : January $25^{\text {th }}, 2018$

Revised date : March $21^{\text {st }}, 2018$

Accepted date : Mei 03 ${ }^{\text {rd, }} 2018$

\section{Keywords:}

Alcoholic beverage

Chromotropic acid

Methanol

\begin{abstract}
An alcoholic beverage contains ethyl alcohol or ethanol $(\mathrm{C} 2 \mathrm{H} 5 \mathrm{OH})$ that is produced from fermentation or distillation of sugars. In many cases, either producers or consumers add ethanol with denaturated alcohol containing methanol $(\mathrm{CH} 3 \mathrm{OH})$ as an additive. Methanol can cause blindness and induce comas, and it is deadly in high doses. This study aimed at investigating the presence of methanol or methyl alcohol in alcoholic beverages sold in Palembang, Indonesia. Seventeen samples collected from small shops and supermarkets were taken by accidental sampling. A chromotropic acid method was used to examine the presence of methanol. The results showed that there were $18 \%$ of samples was positive, and $82 \%$ was negative. Based on alcohol content, the research showed that all (100\%) samples of group A were negative; $33 \%$ of group $\mathrm{B}$ was positive, and $33 \%$ of group $\mathrm{C}$ was positive. The study indicated that methanol was still present in alcoholic drinks sold in markets. The government should inform society that denatured alcohol contains methanol and, therefore, should not be feasible to consume.
\end{abstract}

Corresponding Author:

Diah Navianti

Jurusan Analis Kesehatan Poltekkes Kemenkes Palembang,

JIn. Sukabangun 1 kecamatan sukarame KM 6,5, Palembang, Sumatera Selatan, Indonesia.

Email: dnaviantidiah9@gmail.com

\section{INTRODUCTION}

Indonesia is a country which is rich in both its natural resources and ethnics. Every ethnic has its own culture which is different from one to another.one of the cultures taken as a habit from years ago is the habit of drinking alcohol. A long time ago, the habit of drinking alcohol had become a trend for people in Indonesia. It was usually served as a welcome drink in a palace banquet or served in annual parties such as those after a big harvest. ${ }^{1,2}$ Nowadays, in some regions of Indonesia alcoholic drink is not only consumed at certain moments such as dinner or harvesting but also consumed after social functions or after wedding parties. ${ }^{1}$

Based on the presidential regulation number 74 the Year 2013, alcoholic beverage is a drink that contains ethyl alcohol or ethanol $(\mathrm{C} 2 \mathrm{H} 5 \mathrm{OH})$ which is processed from agricultural products containing carbohydrate using either fermentation with distillation or fermentation without distillation. ${ }^{1,2}$ In The process is selling and consuming, some of the sellers and consumers mix their alcoholic drinks with other 
liquid. Another kind of alcohol which is freely sold in pharmacies and chemical stores is added to increase the quantity or volume but not the alcohol content. The level of alcohol is not changed. In Indonesia, this process of addition is called as "oplosan".

Oplosan drink is highly fatal for humans if consumed. At the beginning of 2014, in Surabaya, 11 people were found dead after consuming oplosan drinks. Three people were also killed in Gresik, and 15 were found dead in Kabupaten Mojokerto. Also, three people in Buleleng dan Bali and four other in Kayuagung, Kabupaten Ogan Komering Ilir, South Sumatra were also reported dead. One man in Kelurahan Kedaton was also reported in critical condition after consuming oplosan drinks. The people were reported dead after having a party of alcoholic drinks in a social function near their house. ${ }^{1}$ From the cases previously mentioned above, it is known that the consumers mix their alcoholic drinks with alcohol for industry (petrochemical) for economical reason. The price of fermented alcohol is far more expensive than that of petrochemical one. Because of that, some drinking industries and manufacturers replace fermented alcohol with petrochemical one as a basic ingredient in the production of alcoholic drinks. However, most people commonly do not know that industrial alcohol (petrochemical) or technical alcohol they use to dilute their drinks has been denatured with benzene and methanol purposively to make them toxic. This is called denatured alcohol. The information about whether the content of alcohol is denatured or not is not stated on its label. Furthermore, the price is very low if compared with fermented one and freely sold. That is why it is easy to get in pharmacies and chemical stores. ${ }^{1}$

This study also collected some samples of alcohol $70 \%$, technical alcohol, and alcohol p.a. which were freely sold in pharmacies and chemical store. The study found that the presence of methanol in alcohol 70 and technical alcohol was positive, but that in alcohol p.a (absolute alcohol) was negative.

Methanol is the simplest part of alcohol. It is liquid, colourless, volatile, and flammable. Furthermore, it is toxic and has distinctive odour. It is usually used for industrial purposes. In industries, methanol is commonly used in paints, adhesive, a foam of cushions, synthetic textile, recycled plastics, and fuel. Methanol is highly toxic to humans. If absorbed, $10 \mathrm{ml}$ of methanol can cause permanent blindness, and $30 \mathrm{ml}$ can lead to death although the literature says that the lethal dose is $100-125 \mathrm{ml}^{3,4}$ When methanol is ingested, it is directly absorbed and distributed throughout the body. Methanol is metabolized in the liver by alcohol dehydrogenase forming formaldehyde, and by aldehyde, dehydrogenase formaldehyde is converted into formic acid. Both metabolites, especially formic acid, can lead to metabolic acidosis and permanent

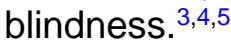

\section{MATERIAL AND METHODS}

\subsection{Research Design}

The research design was a cross-sectional study in which to investigate the presence of methanol in alcoholic beverages sold in Palembang, Indonesia.

\subsection{Research Location}

This cross-sectional study was conducted in July 2015 . The samples of this study were collected from two points of sale (small shops and supermarkets) in Palembang, Indonesia has taken using accidental sampling technique. ${ }^{6}$

\subsection{Population and Sample Size}

All members of the population in this study were taken as samples. The total population of alcoholic beverages which were sold in small shops and supermarkets was 17 bottles. Therefore, all 17 bottles of them were taken as samples. 


\subsection{Data Collection}

Primary data used and analyzed in this study were collected using the following procedures:

a. Laboratory tests. This was used to examine the presence of methanol in samples using chromatropic acid as a qualitative test method.

b. Observation. Through this procedure, supporting data related to samples, i.e. alcohol content, price, points of sale, and packaging characteristic were recorded in a checklist.

\subsection{Principle}

The principle of methanol examination is a qualitative analysis with an indirect method which is based on the oxidation reaction of methanol by potassium permanganate which produces formaldehyde compound. Formaldehyde reacted with the chromotropic acid in concentrate sulfuric acid forming violet compound. ${ }^{7}$

\subsection{Interpretation}

The results of qualitative analysis on the presence of methanol in samples were interpreted as follows:

Positive $(+)=$ violet color appears in test tube.

Negative $(-)=$ no violet colour appears in a test tube.

\subsection{The procedure of Methanol Analysis}

Take $50 \mathrm{~mL}$ of sample in an Erlenmeyer flask. Acidify the sample with H3PO4. Distil slowly into a volumetric flask. Pipette into a test tube five millilitres of chronotopic acid $0.5 \%$ in $\mathrm{H} 2 \mathrm{SO} 460 \%$, and add one $\mathrm{mL}$ distillate slowly and stir the mixture while adding the distillate. Put the test tube in a water bath for 15 minutes and observe the colour changes. The colour of light violet through dark violet indicates the presence of $\mathrm{HCHO}$.

\subsection{Data Analyses}

The obtained raw data were then coded and transformed into certain categories. After that, the data were computed and analyzed statistically both in a univariate and bivariate analysis using computer software. In univariate analysis, each variable was described individually. Using bivariate analysis, then, the dependent variable (the presence of methanol) was described based on independent variables (alcohol content, price, points of sale, and packaging characteristic). ${ }^{6}$

\section{RESULTS AND DISCUSSION}

\subsection{The Presence of Methanol in Alcoholic Beverages}

Based on the laboratory analysis, it was found that $3(18 \%)$ samples were positive and $14(82 \%)$ samples were negative containing methanol. For more details, the results of analysis on the presence of methanol in samples can be seen in Table 1.

Table 1. Frequency Distribution of Methanol in Alcoholic Beverages

\begin{tabular}{ccc}
\hline Methanol & Frequency & Percentage (\%) \\
\hline Positive & 3 & 18 \\
Negative & 14 & 82 \\
\hline Total & 17 & 100 \\
\hline
\end{tabular}


Based on the research, the presence of methanol in samples showed that 3 $(18 \%)$ samples were positive and $14(82 \%)$ samples were negative. Positive results were found in liquors branded $A, B$, and $C$. The result of this study was similar to the findings of Forensic Laboratory of East-Java Regional Police. They found methanol in the evidences they got from binge drinking in Lawang, Kabupaten Malang. The level of methanol in the evidences was $8.3 \%$ and that of ethanol was $19.29 \%$. There were 10 found dead from this case. ${ }^{1}$

There are still many other cases of toxicity as a result of consuming methanoladulterated or methanol-contaminated drinks. In order to get more financial profit, the sellers or consumers add their alcoholic drinks (fermented alcohol). ${ }^{2}$ with other alcohol that they buy in pharmacies or chemical stores in order to increase the volume and effect add other. People do not know that alcohol they buy in pharmacies or chemical stores has been denatured with benzene or methanol to make it toxic and harmful to consume. The alcohol they get from those places is called denatured alcohol. The process of adding alcoholic drinks with others is well known as oplosan. The police can not do much to cope with this problem because denatured alcohol itself is legal to sell in markets. ${ }^{8}$

Methanol causes highly toxical effects in humans. If absorbed, the use of $10 \mathrm{ml}$ absolute methanol will destroy visual nerves and can lead to a permanent blindness, and the use of $30 \mathrm{ml}$ can lead to death although the lethal dose is usually in 100-125 $\mathrm{ml}^{2,3}$ In our body, methanol will be metabolized in liver by alcohol dehydrogenase (DHA) into formaldehyde and later on by formaldehyde dehydrogenase (FDH) converted into formic acid. Both results of metabolism (especially formic acid) are very toxic for our body. ${ }^{9}$

In the cases of methanol poisoning, formaldehyde cannot be detected in victim's body liquid because formaldehyde is quickly converted into formic acid (in 1-2 minutes). Twenty hours later, formic acid is oxidized by 10 -formyl tetrahydrofolate synthetase (F-THF-S) into carbon dioxide compound and water. So, the level of formic acid in body liquid can correlate to methanol poisoning. The symptoms of methanol poisoning mainly depend on the amount of methanol ingested. ${ }^{9}$

\subsection{The Presence of Methanol in Alcoholic Drinks Based on Alcohol Content}

After analysing the presence of methanol qualitatively, the analysis continued on analysing the presence of methanol based on the amount of alcohol in samples. The presence of methanol based on the alcohol content is presented in Table 2.

Table 2. Frequency Distribution of Methanol in Alcoholic Drinks Based on Alcohol Content

\begin{tabular}{|c|c|c|c|c|c|c|c|}
\hline \multirow{2}{*}{ No. } & \multirow{2}{*}{$\begin{array}{l}\text { Alcohol Content } \\
\text { (Group) }\end{array}$} & \multicolumn{4}{|c|}{ Methanol } & \multicolumn{2}{|c|}{ Total (N) } \\
\hline & & Positive & $(\%)$ & Negative & $(\%)$ & Sample & $(\%)$ \\
\hline 1. & A (1\%-5\%) & 0 & 0 & 8 & 100 & 8 & 100 \\
\hline 2. & B (5\%-20\%) & 2 & 33 & 4 & 67 & 6 & 100 \\
\hline 3. & C (20\%-50\%) & 1 & 33 & 2 & 67 & 3 & 100 \\
\hline & Total & 3 & 18 & 14 & 82 & 17 & 100 \\
\hline
\end{tabular}

Based on Table 2, it is known that from 8 samples of group A, all $(100 \%)$ were negative; from 6 samples of group B, 2 (33\%) were positive and $4(67 \%)$ were negative; and from 3 samples of group C, 1 (33\%) was positive and $2(67 \%)$ were negative. The presence of methanol based on alcohol content found that all $(100 \%)$ 
samples of group A were negative, $33 \%$ of group B was positive, and $33 \%$ of group C was positive. The result of this study supported the cause of deaths of alcohol poisoning occurred in Kayu Agung, Ogan Ilir, South Sumatra. The other related cases were also found in other regions such as Kecamatan Kota Baru and Kecamatan Cikampek, Kabupaten Karawang. The liquors they 'oplos' were from branded ones.

Poisoning from consuming beverages containing low alcohol belonging to group A $(1 \%-5 \%)$ is rarely to find. Because alcohol drinks of group $A$ is prepared by fermentation, the effects are only causing relaxation and lessening stress, inhibiting concentration, and slowing reflect. The fermentation can be done in a short time (1-2 weeks) to produce ethanol in the level of $3-8 \%$. On the contrary, those of group B $(5 \%$ - 20\%) and group C (20\%-50\%) are prepared by distillation. Therefore, it needs longer time (months even years) to reach those levels. The level of ethanol obtained from this process is only $7-13 \%$. Instead of long process and complicated way to prepare distilled alcohol, the sellers and consumers use denatured one as an alternative. Denatured alcohol is cheap and easy to find. Furthermore, by mixing with denatured ones, the level of alcohol can be adjusted and the effects as they want can be got. So, it can be said that most alcohol poisonings are mainly caused by consuming beverages containing high amount of alcohol (group B and C) which is contaminated by methanol. 4,10

\subsection{The Presence of Methanol in Alcoholic Beverages Based on Price}

The next analysis of this study was on the presence of methanol in alcoholic beverages based on the price. The presence of methanol based on price can be seen in Table 3.

Table 3. Frequency Distribution of Methanol in Alcoholic Beverages Based on Price

\begin{tabular}{cccccccc}
\hline \multirow{2}{*}{ No. } & \multirow{2}{*}{ Price (IDR) } & \multicolumn{4}{c}{ Methanol } & \multicolumn{3}{c}{ Total } \\
\cline { 3 - 8 } & & Positive & $(\%)$ & Negative & $(\%)$ & Sample & $(\%)$ \\
\hline 1. & $15,000-25,000$ & 3 & 20 & 12 & 80 & 15 & 100 \\
2. & $25,000-30,000$ & 0 & 0 & 2 & 100 & 2 & 100 \\
\hline & Total & 3 & 18 & 14 & 82 & 17 & 100 \\
\hline
\end{tabular}

Based on Table 3, it is known that from 15 samples of 15,000-25.000 IDR, 3 $(20 \%)$ were positive and $12(80 \%)$ were negative. Meanwhile, from 2 samples of $25,000-30,000$ IDR, all (100\%) were negative. The presence of methanol based on price found that $20 \%$ of samples of $15,000-25,000$ IDR was positive and all (100\%) samples of 25,000-30,000 IDR were negative. The result of this study supported the cause of poisoning in which the victims only thought of cheap price without considering the lethal effect from the drinks they consume. The price of alcoholic drinks produced from pure fermentation is not cheap if compared with those that consumers get from illegal points of sale. For example, $J D$ is sold for 500,000 IDR per bottle while fake $J D$ is sold at a price of 100,000 IDR.

The price of oplosan drinks is usually not until hundreds thousands rupiah because the content is not pure ethanol from fermentation. Most sellers and consumers frequently use concentrated alcohol that is easy to find in chemical stores or pharmacies. These alcohols are sold at very cheap price compared with fermented one.

\subsection{The Presence of Methanol in Alcoholic Drinks Based on Points of Sale}

The analysis continued on the presence of methanol in alcoholic beverages based on points of sale. Points of sale were also assumed to have contribution to the 
presence of methanol in alcoholic beverages. The presence of methanol based on points of sale is presented in Table 4.

Table 4. Frequency Distribution of Methanol in Alcoholic Beverages Based on Points of Sale

\begin{tabular}{cccccccc}
\hline \multirow{2}{*}{ No. } & \multirow{2}{*}{$\begin{array}{c}\text { Points } \\
\text { of Sale }\end{array}$} & \multicolumn{4}{c}{ Methanol } & \multicolumn{3}{c}{ Total } \\
\cline { 3 - 8 } & Positive & $(\%)$ & Negative & $(\%)$ & Sample & $(\%)$ \\
\hline 1. & Small shops & 3 & 23 & 10 & 77 & 13 & 100 \\
2. & Supermarkets & 0 & 0 & 4 & 100 & 4 & 100 \\
\hline & Total & 3 & 18 & 14 & 82 & 17 & 100 \\
\hline
\end{tabular}

Based on Table 4, it is known that from 13 samples collected from small shops on the streets, $3(23 \%)$ samples were positive and $10(77 \%)$ samples were negative. Meanwhile, from 4 samples taken from supermarkets, all (100\%) were found negative. The presence of methanol based on alcohol content found that from 13 samples collected from small shops on the streets, 3 (23\%) samples were positive and $10(77 \%)$ samples were negative. Meanwhile, from 4 samples taken from supermarkets, all $(100 \%)$ were found negative. The result of this study supported the causes of many alcohol poisonings among society after they consumed those got from small shops. The sellers did not have any legal permission to sell this liquor and they did not have any trainings on how to dillute alcohol without causing any lethal effects. ${ }^{8}$

Based on presidential regulation number 74/2013 on the controlling and monitoring of production, distribution, and selling of alcoholic beverages, alcoholic beverages can only be sold with legal permission from Ministry of Trade. Regarding this regulation, alcoholic drinks group $A, B$, and $C$ can only be sold in hotels, bars, restaurants, duty-free shops, and other certain points of sale that have been approved by local government and have met standard requirements as regulated by tourism offices. Furthermore, this also regulates that these points of sale may not be located near places of worship, educational institurtions, and hospitals. Apart from these points of sale, only alcoholic drinks group A can be sold. ${ }^{8}$

From the research observation, it was found that many sellers of liquor did not have permission to legalize their jobs. In addition, they sold any groups of alcohol freely without considering whether they were legal or not to sell in their places. They also did not care about negative effects coming from these illegal practices. The lack of monitoring and controlling from the police and local government could also contribute to these problems. ${ }^{5,8}$

\subsection{The Presence of Methanol in Alcoholic Beverages Based on Packaging Characteristics}

The analysis continued on the presence of methanol in alcoholic beverages based on packaging characteristics. Packaging characteristics were also assumed to have contribution to the presence of methanol in alcoholic beverages. The presence of methanol based on packaging characteristics is presented in Table 5. 
Table 5. Frequency Distribution of Methanol in Alcoholic Beverages Based on Packaging Characteristics

\begin{tabular}{cccccccc}
\hline \multirow{2}{*}{ No. } & Packaging & \multicolumn{4}{c}{ Methanol } & \multicolumn{3}{c}{ Total } \\
\cline { 3 - 8 } & Characteristic & Positive & $(\%)$ & Negative & $(\%)$ & Sample & $(\%)$ \\
\hline 1. & Appropriate & 3 & 21 & 11 & 79 & 14 & 100 \\
2. & Inappropriate & 0 & 0 & 4 & 100 & 4 & 100 \\
\hline & Total & 3 & 18 & 14 & 82 & 17 & 100 \\
\hline
\end{tabular}

Based on Table 5, it is known that from 14 samples with appropriate packaging, 3 $(21 \%)$ were found positive and $11(79 \%)$ were found negative. Meanwhile, 4 samples with inappropriate packaging were found all negative.

The presence of methanol based on packaging characteristic found that from 14 samples with appropriate packaging, $3(21 \%)$ were positive and 11 (79\%) were negative. Meanwhile, 4 samples with inappropriate packaging were all negative, from the results above, 3 samples with appropriate packaging were positive methanol. This could happen because either the sellers or consumers made use of used bottles of softdrinks or alcoholic drinks as the alcohol containers. These bottles were cleaned, washed without destroying the label, dried, refilled, and labelled with fake ones. This is one of the ways that the sellers use to trick the consumers, government or police. However, we can differentiate whether it is an oplosan or not by checking the information on its label such as production date, expiry date, BPOM registration, seal, and price. ${ }^{8}$

\section{CONCLUSIONS}

Methanol has been found in "oplosan" beverages sold and has exceeded the threshold. Require optimal supervision from various parties concerned to supervise the circulation of "oplosan" drinks containing methanol above the threshold.

\section{ACKNOWLEDGEMENT}

We would like to thank to all faculty members of Medical Laboratory Science of Poltekkes Kemenkes Palembang and all those who had contributed to to this research.

\section{References}

1. Surya online, Miras oplosan pembawa maut (positif mengandung etanol dan metanol). 2014.

2. Lachenmeier, P. T. H. Anh, S. Popova, and J. Rehm, "The quality of alcohol products in Vetnam and its implications for public health," Int. J. Environ. Res. Public Health, vol. 6, no. 8, pp. 2090-2101, 2009.

3. Barile, Clinical Toxicology Principles and Mechanisms. London, new york, Washington, D.C: The taylor \& Francis e-library, 2005.

4. Kraut A, Jeffrey; Kurtz, "Toxic Alcohol Ingestions: Clinical Features, Diagnosis, and Management," Clin. J. Am. Soc. Nephrol., 2008.

5. Shalini Rehm, Jürgen; Kailasapillai, "A systematic review of the epidemiology of unrecorded alcohol consumption and the chemical composition of unrecorded alcohol," willey online Libr., 2014.

6. Kuzma, Basic Statistics for the health sciences. California: Mayfield Publishing Company, 1984.

7. Flanagan, R.A. Braithwaite, S.S. Brown, B. Widdop, "Analytical_Toxicology.Pdf." world health organization, Geneva, 1995. 
8. BadanPOM, "TOPIK SAJIAN UTAMA : Menilik Regulasi Minuman Beralkohol di Indonesia," vol. 15, no. 3, 2014.

9. WHO, Biological monitoring of chemical exposure in the workplace, Volume 2. geneva: Finnish institute of occupational health, 1996.

10. Álvarez-ainza, H. González-ríos, A. González-león, Á. J. Ojeda-contreras, A. I. Valenzuela-quintanar, and E. Acedo-félix, "Quantification of Mayor Volatile Compounds from Artisanal Agave Distilled: Bacanora," Am. J. Anal. Chem., vol. 2013, no. November, pp. 683-688, 2013. 